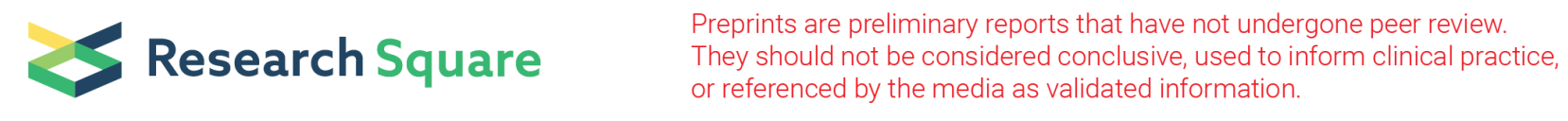

\title{
Survival Benefits of Androgen Receptor Signaling-Axis Inhibitor's at The Cost of Adverse Event Occurrence: A Systematic Review and Meta-Analysis of Randomized Controlled Trials
}

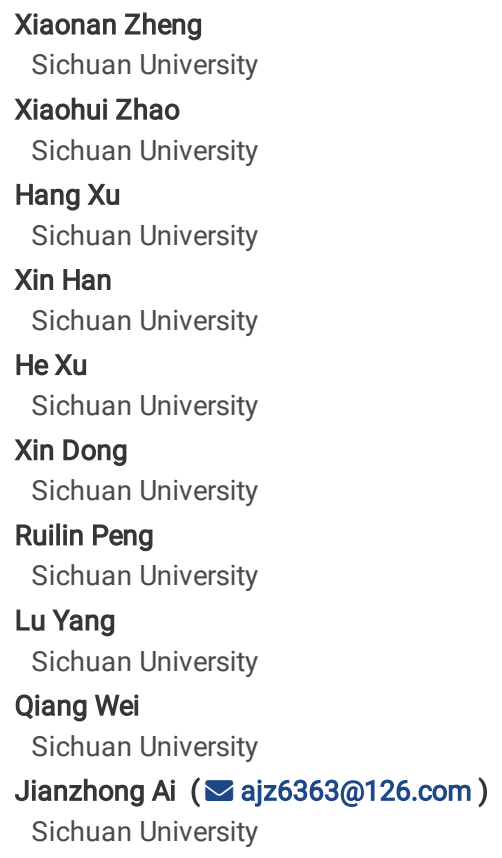




\section{Abstract}

Background: Previous evidence directly evaluating the efficacy and safety of the treatment for castration-resistant prostate cancer (CRPC) by androgen receptor (AR) signaling-axis inhibitors was limited by the quantity of randomized controlled trials (RCT) and biased by non-RCTs. We aim to comprehensively assess the efficacy and safety of abiraterone and enzalutamide using only RCTs. Patients and methods: We systematically searched Pubmed, Embase, MEDLINE and ClinicalTrial.gov for RCTs providing data of treatment outcomes by AR inhibitors (abiraterone and enzalutamide). Pooled hazard ratios (HR) with $95 \% \mathrm{Cl}$ for survival benefits were calculated using STATA 12.0. Comparison of prostate-specific antigen (PSA) response rate, aggregated adverse event (AE) statistics, any grade $A E$, high-grade $A E$ (grade $\geq 3$ ), AE of special interest between the treatment and control groups were performed by RevMan 5.3 and STATA 12.0. Results: Eight eligible RCTs with 6296 patients were selected. Pooled HR were 0.72 for overall survival, 0.45 for radiographic progression-free survival and 0.36 for PSA PFS. AR inhibitors could significantly increase the rate of PSA response $(\mathrm{OR}=8.67,95 \% \mathrm{Cl} 4.42-17.04)$ and $\mathrm{AE}$ occurrence $(\mathrm{OR}=1.98$, $95 \% \mathrm{Cl} 1.46-2.68)$. The treatment group had a higher occurrence of any-grade fatigue (OR=1.34, 95\% $\mathrm{Cl} 1.20-1.49)$, back pain (OR=1.15, 95\% $\mathrm{Cl} 1.01-1.15)$, hot flush $(\mathrm{OR}=1.76,95 \% \mathrm{Cl} 1.50-2.06)$, diarrhea $(\mathrm{OR}=1.22,95 \% \mathrm{Cl} 1.07-2.40)$ and arthralgia $(\mathrm{OR}=1.34,95 \% \mathrm{Cl} 1.16-1.54)$. Particularly, the outcomes for $\mathrm{AEs}$ of special interest including any grade hypertension $(\mathrm{OR}=2.06,95 \% \mathrm{Cl} 1.71-2.47)$, hypokalemia $(\mathrm{OR}=1.80,95 \% \mathrm{Cl} 1.42-2.30)$ and fluid retention or edema (OR=1.38,95\% $\mathrm{Cl}$ 1.17-1.63) also favored the control group. In terms of high-grade $A E s$, a higher occurrence of hypertension $(O \mathrm{R}=2.60,95 \% \mathrm{Cl} 1.79-3.79)$ and pain in extremity $(\mathrm{OR}=4.46,95 \% \mathrm{Cl} 2.81-7.07)$ was observed in the treatment group. There was no significant difference regarding other AEs analyzed in this study. Conclusion: The survival benefits by AR inhibitors for CRPC were evident and promising at the cost of acceptably higher risk of AEs occurrence.

\section{Background}

Prostate cancer is the most common cancer in men in the United States ${ }^{1,2}$. Regardless the indolent course of many tumors and excellent prognosis of localized prostate cancer, advanced prostate cancer is extremely fatal. Androgen deprivation therapy (ADT) is the standard therapy for advanced prostate cancer $^{3}$. Most patients initially respond to castration but progression of disease will eventually appear ${ }^{4}$, in which tumor escape mechanism is believed to be employed by CRPC to overcome ADT and cause subsequent mortality ${ }^{5}$.

Docetaxel and bicalutamide are commonly use as the first line therapy for advanced prostate cancer before two new androgen receptor axis-signaling

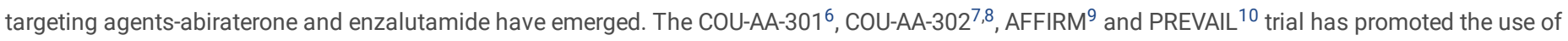
abiraterone and enzalutamide, and several subsequent trials also evaluated the efficacy of abiraterone and enzalutamide. However, few meta-analyses have included all the related RCTs and directly pooled the HR of OS and PFS by these two agents. In addition, although some previous studies have tried to investigate the efficacy and safety of abiraterone and enzalutamide, evidence regarding AR inhibitors as a whole was scanty and their analysis was either indirect or subjected to bias caused by non-RCTs ${ }^{11-14}$. Moreover, comparison of the occurrence high-grade AEs (grade $\geq 3$ ) between the AR inhibitor and control groups has been lacking.

In this meta-analysis, we aim to confirm the efficacy and safety of androgen receptor axis-signaling targeting agents by directly calculating the pooled HR of OS and PFS and pooled OR of PSA response rate by abiraterone and enzalutamide compared with the control group. Meanwhile, the occurrence of AEs (anygrade and high-grade) was compared between AR inhibitor and control groups. Furthermore, subgroup analysis was conducted to make a comparison between abiraterone and enzalutamide.

\section{Methods}

\subsection{Search strategy and Inclusion criteria}

PRISMA guidelines were followed to perform this systematic review and meta-analysis ${ }^{15}$. Two investigators independently searched Pubmed, Embase, MEDLINE and ClinicalTrials.gov for phase 2 and 3 RCT (randomized clinical trial) published up to Aug 1, 2018. The search strategy included terms: "castration-resistant prostate cancer", "CRPC", "androgen receptor", "CYP17A1", "cytochrome P450 17A1", "abiraterone”, "enzalutamide", "efficacy", "survival”, "safety", and "adverse". References cited by the finally selected articles were also reviewed.

RCT assessing the efficacy and safety of inhibitors of androgen receptor, CYP17A1 inhibitor in CRPC patients and providing data of HR with 95\% Cl were potentially eligible. The detailed inclusion criteria are as following: 1. RCT; 2 . literature evaluating Abiraterone and/or Enzalutamide efficacy against control; 3. One and only one of abiraterone or enzalutamide was used in the experimental group rather than in the control group; 4 . Efficacy indicators including OS and/or PFS, or adverse events must be reported; 5 . Hazard ratio and $95 \%$ confidential interval must be available regarding the efficacy; 6 . Literature must be published in English. We excluded articles 1) that were non-RCT, that is non-English; 2) that did not either assess the efficacy or reported the adverse events of abiraterone and enzalutamide; 3 ) in which other agents that might deviate the conclusion were used among the experimental group; 4) in which abiraterone and enzalutamide were used together for the experimental group; 5) in which abiraterone and enzalutamide were regarded as the control group. Duplicate articles from the same RCT were screened and excluded

\subsection{Data analysis}

Two investigators independently extracted data from the included articles and all the members of our team resolved the discrepancies by consensus. Data includes: clinical trial code (NCT), study name, study phase, study size, drugs for experimental and control group, median age, percentage of patients with PSA decline $\geq 50 \%$, the definition of PFS and median OS and PFS.

The primary outcome was the efficacy of abiraterone and enzalutamide on the whole population of enrolled patients, for which pooled HR for PFS and OS was calculated respectively using random-effect models. In addition, PSA response rate (defined as at least 50\% PSA decline from baseline) was compared 
between the treatment and control groups. Subgroup analysis of PFS according to the type of AR inhibitors was also conducted. Heterogeneity between different $A R$ inhibitors were assessed. $P_{\text {heterogeneity }}<0.05$ was regarded as statistically significant.

The second outcome was the comparison of aggregated $A E$ statistics (any $A E$, high grade $A E$ (grade $\geq 3$ ), $A E$ leading to death, $A E$ leading to discontinuation and any serious $A E$ ), and the occurrence of any grade $A E, A E$ of special interest and high-grade $A E$ (grade $\geq 3$ ) between the treatment and control groups. To maximally eliminate the potential bias caused by the various reporting standard of AE occurrence in those selected trials, we extracted data of AEs that occurred among at least $10 \%$ of either the AR inhibitor group or the control group. In addition, to make our data more statistically powerful and conclusion more convincing, AEs reported in at least three trials were included for comparison. In the forest plot for comparison, when the points of the diamond did not overlap the vertical line, a significant difference between the treatment and control groups was indicated.

Q-test and $R$ was employed to evaluate the heterogeneity between studies. When a high heterogeneity $(R>50 \%)$ occurred between studies, sensitivity analysis was utilized to find the source of heterogeneity by following steps: remove each trial in the analysis recalculate the heterogeneity; When heterogeneity remains high after trials are individually removed, we analyze the trials themselves and figure out the reasonable sources of high heterogeneity.

All the mentioned analysis was completed using STATA (version 12.0) and images were processed with Photoshop (version CS6)

\subsection{Quality assessment}

The methodological quality of included trials was assessed by the Jadad ranking system ${ }^{16}$. An RCT could be given a Jadad score of between 0 (poor) and up to 5 (optimal) according to the quality of randomization, double-blinding and follow-up.

\section{Results}

\subsection{Study characteristics}

From the 489 retrieved publications, we selected 84 potentially eligible articles for abstract and full articles review. Eventually 8 RCTs with 10 articles met the inclusion criteria ${ }^{6-10,17-21}$, which were published from 2012 to 2017 (figure 1 and table 1 ). Two trials were phase 2, while six trials were phase 3 . Five trials were conducted in first-line fashion and three with second-line (table 1). For each trial, the number of CRPC patients ranged from 196 to 1199 , and a total of 6290 patients were included. 2804 patients (44.6\%) were enrolled in abiraterone trials and $3486(55.4 \%)$ in enzalutamide trials. The median age of enrolled patients varied from 68 to 74 with two trials reported mean ages.

The superiority of the experimental group over the control group was shown for PSA response (prostate-specific antigen level decline $50 \%$ or more from baseline) rate reported in seven studies. The rate of PSA decline $\geq 50 \%$ in the experimental group ranged from $5.1 \%$ to $90.9 \%$. compared with $1.3 \%$ to $42.0 \%$ in the control group. The median overall survival was reported in four studies and the increased duration in the experimental group varied from 4.0 months to 4.6 months compared with the control group. Overall PFS, radiographic PFS and PSA PFS were reported asymmetrically in those trials. Still, the median PFS was generally longer in the AR inhibitor group regarding either overall PFS, radiographic PFS or PSA PFS.

\subsection{Overall survival, progression-free survival and PSA response rate}

Figure 2 presented the efficacy of abiraterone and enzalutamide among all the enrolled participants. HR with $95 \% \mathrm{Cl}$ for OS was assessed in five trials while HR with $95 \% \mathrm{Cl}$ for radiographic PFS and PSA PFS were both assessed in six trails. Patients treated with abiraterone and enzalutamide had greater survival benefits with pooled HR for OS ( $\mathrm{HR}=0.72,95 \% \mathrm{Cl} 0.67-0.78)$, radiographic PFS ( $\mathrm{HR}=0.45,95 \% \mathrm{Cl} 0.42-0.48)$ and PSA PFS (HR=0.36,95\% $\mathrm{Cl} 0.32-0.40)$, respectively. PSA response rate was evaluated in figure 3. Patients treated with $\mathrm{AR}$ inhibitors had a significantly higher rate of $\mathrm{PSA}$ response $(\mathrm{OR}=10.15,95 \% \mathrm{Cl}$ 8.07-12.28, $\mathrm{P}<0.00001$ ) than the control group did.

In addition, we also conducted a subgroup analysis according to the different type of AR inhibitor (supplementary figure s1, s2 and s3). It seemed enzalutamide had greater efficacy than abiraterone in either rPFS (HR: 0.36 vs $\left.0.60, P_{\text {heterogeneity }}<0.05\right)$, PSA PFS (HR: 0.24 vs $0.57, P_{\text {heterogeneity }}<0.05$ ) or PSA response rate (OR: 21.88 vs $\left.4.69, P_{\text {heterogeneity }}<0.05\right)$, but not in overall survival (HR: 0.71 vs $\left.0.78, P_{\text {heterogeneity }}=0.319\right)$ ).

\subsection{Aggerated adverse events statistics}

As figure 4 displayed, the AR inhibitor group had a higher probability of occurrence of any-grade $A E(O R=1.98,95 \% C l 1.46-2.68, P<0.0001)$. However, no significant difference was found between the treatment and control group in regard to occurrence of high-grade $A E$ (grade $\geq 3$ ), $A E$ leading to death, $A E$ leading to discontinuation and any serious $A E$, even though the $A R$ inhibitor group had a virtually significantly lower chance of high-grade $A E(O R=0.91$, $95 \%$ CI $0.82-$ $1.01, P=0.08)$

\subsection{Any-grade adverse events}

Figure 5A displayed any-grade AEs with significant difference between the AR inhibitor and control groups. As the forest plots showed, patients in the treatment group experienced higher rate of any-grade fatigue $(\mathrm{OR}=1.34,95 \% \mathrm{Cl} 1.20-1.49, \mathrm{P}<0.00001)$, back pain $(\mathrm{OR}=1.15,95 \% \mathrm{Cl} 1.01-1.15, \mathrm{P}=0.03)$, hot flush $(\mathrm{OR}=1.76,95 \% \mathrm{Cl} 1.50-2.06, \mathrm{P}<0.00001)$, diarrhea $(\mathrm{OR}=1.22,95 \% \mathrm{Cl} 1.07-2.40, \mathrm{P}=0.003)$, and arthralgia (OR=1.34, 95\% Cl 1.16-1.54, $\mathrm{P}<0.001)$. No significant difference was observed in constipation ( $\mathrm{OR}=1.13,95 \% \mathrm{Cl} 0.98-1.29, \mathrm{P}=0.09)$ bone pain, pain in extremity, anemia, tract infection and nausea (supplementary figure S4). 
Outcomes for AEs of special interest (Figure 5B), including any-grade hypertension (OR=2.06, 95\% Cl 1.71-2.47, $\mathrm{P}<0.00001)$, hypokalemia (OR=1.80, 95\%Cl

$1.42-2.30, \mathrm{P}<0.00001)$ and fluid retention or edema $(\mathrm{OR}=1.38,95 \% \mathrm{Cl} 1.17-1.63, \mathrm{P}=0.0001)$ all significantly favored the control group.

\subsection{High-grade (grade $\geq 3$ ) adverse events}

In terms of high-grade $\mathrm{AEs}$, a higher risk of hypertension ( $\mathrm{OR}=2.60,95 \% \mathrm{Cl} 1.79-3.79, \mathrm{P}<0.00001)$ and pain in extremity $(\mathrm{OR}=4.46,95 \% \mathrm{Cl} 2.81-7.07, \mathrm{P}<0.00001)$ in the AR inhibitor group was observed (Figure 5C). There were no significant differences in high-grade fatigue, back pain, constipation, diarrhea, hot flush, fluid retention or edema, urinary tract infection, falls, or decreased appetite between the treatment and control groups. (supplementary figure S5)

\subsection{Quality assessment}

All trials employed randomized treatment allocation sequences, and three of them were computer-generated random number or using similar fashion. All trials were double blinded. Jadad scores were given to each trial and listed in table 2 . The mean score was 4.25 and all trials were ranked as high quality.

\section{Discussion}

As a selective inhibitor of androgen biosynthesis, abiraterone acetate can irreversibly and potently block CYP17, a crucial enzyme in testosterone and estrogen synthesis, resulting in virtually undetectable serum and intratumoral androgens ${ }^{22,23}$, while enzalutamide can impair nuclear translocation of the androgen receptor and its binding to NDA, leading to reduced expression of androgen-dependent genes ${ }^{23,24}$. Although their mechanism is unique but they are both AR inhibitors. In this study, the data we collected showed that AR inhibitors could provide a maximal median OS of 35.3 months, median PFS of 20 months and PSA response rate of $90.9 \%$. By the fashion of pooled HR, we confirmed that patients diagnosed with CRPC had evidently greater survival benefits after being treated with AR inhibitors compared to controls (OS: HR=0.72; rPFS: HR=0.45; PSA PFS: HR=0.36). To our knowledge, this is the first meta-analysis that directly calculated the pooled HR of OS and PFS of AR inhibitors with the original HR data provided in trials. Previous study conducted by Fang ${ }^{13}$ also pretended to pool the HR based on median OS and PFS and a method stated by Cortes ${ }^{25}$. However, as the authors explained, the estimated HR value could bring considerable uncertainty and was weakly convincing.

PSA response rate was another commonly used marker as an efficacy measure for CRPC response. Although the clinical significance of PSA response rate was not completely clear ${ }^{26}$. Smith claimed higher PSA response rate was associated with longer survival time ${ }^{27}$, despite the meta-analysis conducted by Zheng ${ }^{11}$ found inconsistent results. Due to the data insufficiency in our study, we could not evaluate the correlation between PSA response rate and survival time. However, given that our study displayed that AR inhibitor group had a significantly higher PSA response rate, it's concluded that the efficacy of AR inhibitors for CRPC was quite promising.

The reliability of the efficacy of abiraterone was proved by Zhou ${ }^{12}$, and our subgroup outcomes suggested similar conclusions as theirs. Moreover, several prior studies had insights into the comparison between abiraterone and enzalutamide. To confirm their conclusions, we also performed subgroup analysis and evaluate the heterogeneity between abiraterone and enzalutamide. With limited number of RCTs included, Zhang ${ }^{14}$ indirectly compared the OS, PSA PFS, rPFS and PSA response rate of abiraterone with those of enzalutamide. Consistent to our findings, they claimed enzalutamide outperformed abiraterone in terms of PSA PFS, rPFS and PSA response rate. However, there was no significant difference in regard to OS. Similarly, Zheng ${ }^{11}$ also found enzalutamide brought greater benefits of PFS but not of OS, although it's an indirect comparison and only two trials were included.

In addition, we comprehensively explore the safety of abiraterone and enzalutamide by showing that AR inhibitors could lead to higher rates of any-grade AE occurrence, virtually significantly lower rates of high-grade (grade $>=3$ ) $A E$, and similar rates of $A E$ leading to death or discontinuation. In Zheng's study ${ }^{11}$, they also evaluated the safety of abiraterone and enzalutamide, although less AEs were involved. Also, given that only COU-AA-302 trial and PREVAIL trial were respectively included for analysis in their study, the statistical power was relatively low. Our meta-analysis suggested that patients treated with AR inhibitors had a higher occurrence of any-grade fatigue, back pain, hot flush, diarrhea, arthralgia, hypertension, hypokalemia, fluid retention or edema. When it came to high-grade $A E$, hypertension and pain in extremity were associated with AR inhibitors. Even though, the safety of abiraterone and enzalutamide seemed acceptable and controlled, since those AEs could be generally managed by appropriate medical monitoring ${ }^{12}$ and our meta-analysis also suggested they would not lead to more frequent death. Still, those AEs were less lethal compared with AEs caused by cytotoxic therapy ${ }^{28}$. Measures including, for instance, a higher dosage of antihypertensive drugs, oral potassium supplementation and analgesics are required to manage these AEs whilst AR inhibitor treatment.

Notably, inter-study heterogeneity was generally low except only in the analyses of PFS, any-grade hot flush, hypertension and hypokalemia, which perhaps could be explained by the different line of treatment and heterogeneity between abiraterone and enzalutamide ${ }^{29,30}$. Considering a limitation of our study is relied on the published results rather than on original individual patients' data, some important baseline characteristics of the patients, i.e., age, bone lesion, visceral disease and Eastern Cooperative Oncology Group (ECOG) performance status score, along with GS, might also play a crucial role in this substantial heterogeneity. It's also likely that particular other unknown patient characteristics would cause so.

One advantage of this study is the employment of pooled HR value to assess the efficacy of AR inhibitors. Compared with median value of OS and PFS, HR value takes both time and cohort size into consideration. Furthermore, all the data included for analysis were collected from a large population in high-quality RCTs. Therefore, our outcomes are more statistically powerful and convincing. Concerning the multiple definition of PFS, to eliminate the potential bias and make the outcomes more accurate, we categorized PFS into radiographic and PSA related, which actually had clinical significance. Also, as a host of metaanalyses have been conducted to compare abiraterone and enzalutamide, we did not only assess AR inhibitors as a whole but also performed subgroup analysis to study them separately. Unlike previous meta-analyses, we did not only evaluate the safety of abiraterone and enzalutamide by any-grade AEs, but 
also focused on high-grade AEs, which is in fact critical and practical since high-grade AEs are more likely to cause mortality, even if we found AR inhibitors were only associated with more common occurrence of high-grade hypertension and pain in extremity.

Our study should not be interpreted without limitations. First of all, the amount of included RCTs still seems insufficient, especially in the subgroup analysis comparing abiraterone and enzalutamide, although we have systematically searched available databases and cross-referenced the identified articles. Another limitation is that the variations in included studies, for instance, the baseline PSA and GS, different inclusion and exclusion criteria and follow-up therapy, could affect the individual survival outcomes and subsequent pooled outcomes. The third limitation is the substantial heterogeneity found in some of the analyses. In our meta-analysis, six trials were first-line setting and only two were second-line setting. However, Zhang ${ }^{14}$ has investigated the optimal treatment sequencing using the same second-line setting trials included in our studies, so we did not perform the same analysis. Last but not the least, data loss was common when we performed analysis for AE occurrence due to the different reporting standards in trials. To minimize the potential bias, we only extracted data strictly meeting our inclusion criteria, causing an army of AEs were not included for analysis.

Accordingly, in the future clinical practice, AR inhibitors should be considered as an efficacious and safe treatment option for CRPC patients, even though practioners should pay special attention to AEs mentioned in our study, particularly the high-grade AEs. Also, it would be meaningful for investigators conducting the original researches to use a uniformed AE reporting standard for the aim of further and deeper data analysis.

\section{Conclusions}

Our study suggested the survival benefits by AR inhibitors for CRPC were evident and promising at the cost of acceptably higher risk of AEs occurrence.

\section{Declarations}

\section{- $\quad$ Ethics approval and consent to participate}

Not Applicable

- $\quad$ Consent to publish

All authors agree to publish

\section{- $\quad$ Availability of data and materials}

All data and materials were listed in the manuscript

\section{- $\quad$ Competing interests}

Not Applicable

- $\quad$ Funding

This research is supported by the National Natural Science Foundation of China (Grant No. 81702536, 81770756), Programs from Science and Technology De

\section{- $\quad$ Authors' Contributions}

Xiaonan Zheng, Xiaohui Zhao and Hang Xu searched the literature and analyzed data. Xin Han, He Xu, Xin Dong, Ruilin Peng and Lu Yang drafted and polished the manuscript. Qiang Wei and Jianzhong Ai conceived the project.

\section{- $\quad$ Acknowledgements}

Not Applicable

\section{References}

1. Miller KD, Siegel RL, Lin CC, et al. Cancer treatment and survivorship statistics, 2016. CA: a cancer journal for clinicians. Jul 2016;66(4):271-289.

2. Siegel RL, Miller KD, Jemal A. Cancer Statistics, 2017. CA: a cancer journal for clinicians. Jan 2017;67(1):7-30.

3. Lam JS, Leppert JT, Vemulapalli SN, Shvarts O, Belldegrun AS. Secondary hormonal therapy for advanced prostate cancer. The Journal of urology. Jan 2006;175(1):27-34.

4. Eisenberger MA, Blumenstein BA, Crawford ED, et al. Bilateral orchiectomy with or without flutamide for metastatic prostate cancer. The New England journal of medicine. Oct 8 1998;339(15):1036-1042. 
5. Higano CS, Crawford ED. New and emerging agents for the treatment of castration-resistant prostate cancer. Urologic oncology. Nov-Dec 2011;29(6 Suppl):S1-8.

6. Fizazi K, Scher HI, Molina A, et al. Abiraterone acetate for treatment of metastatic castration-resistant prostate cancer: final overall survival analysis of the COU-AA-301 randomised, double-blind, placebo-controlled phase 3 study. The Lancet. Oncology. Oct 2012;13(10):983-992.

7. Ryan CJ, Smith MR, de Bono JS, et al. Abiraterone in metastatic prostate cancer without previous chemotherapy. The New England journal of medicine. Jan 10 2013;368(2):138-148.

8. Ryan CJ, Smith MR, Fizazi K, et al. Abiraterone acetate plus prednisone versus placebo plus prednisone in chemotherapy-naive men with metastatic castration-resistant prostate cancer (COU-AA-302): final overall survival analysis of a randomised, double-blind, placebo-controlled phase 3 study. The Lancet. Oncology. Feb 2015;16(2):152-160.

9. Scher HI, Fizazi K, Saad F, et al. Increased survival with enzalutamide in prostate cancer after chemotherapy. The New England journal of medicine. Sep 27 2012;367(13):1187-1197.

10. Beer TM, Armstrong AJ, Rathkopf D, et al. Enzalutamide in Men with Chemotherapy-naive Metastatic Castration-resistant Prostate Cancer: Extended Analysis of the Phase 3 PREVAIL Study. European urology. Feb 2017;71(2):151-154.

11. Zheng H, Chen J, Qiu W, et al. Safety and Efficacy of First-Line Treatments for Chemotherapy-Naive Metastatic Castration-Resistant Prostate Cancer: A Systematic Review and Indirect Comparison. 2017;2017:3941217.

12. Zhou ZR, Liu SX, Zhang TS, Xia J, Li B. Abiraterone for treatment of metastatic castration-resistant prostate cancer: a systematic review and metaanalysis. Asian Pacific journal of cancer prevention : APJCP. 2014;15(3):1313-1320.

13. Fang M, Nakazawa M, Antonarakis ES. Efficacy of Abiraterone and Enzalutamide in Pre- and Postdocetaxel Castration-Resistant Prostate Cancer: A TrialLevel Meta-Analysis. 2017;2017:8560827.

14. Zhang W, Wu TY, Chen Q, et al. Indirect comparison between abiraterone acetate and enzalutamide for the treatment of metastatic castration-resistant prostate cancer: a systematic review. Asian journal of andrology. Mar-Apr 2017;19(2):196-202.

15. McInnes MDF, Moher D, Thombs BD, et al. Preferred Reporting Items for a Systematic Review and Meta-analysis of Diagnostic Test Accuracy Studies: The PRISMA-DTA Statement. Jama. Jan 23 2018;319(4):388-396.

16. Jadad AR, Moore RA, Carroll D, et al. Assessing the quality of reports of randomized clinical trials: is blinding necessary? Controlled clinical trials. Feb $1996 ; 17(1): 1-12$.

17. Sun Y, Zou Q, Sun Z, et al. Abiraterone acetate for metastatic castration-resistant prostate cancer after docetaxel failure: A randomized, double-blind, placebo-controlled phase 3 bridging study. International journal of urology : official journal of the Japanese Urological Association. May 2016;23(5):404411.

18. Ye D, Huang Y, Zhou F, et al. A phase 3, double-blind, randomized placebo-controlled efficacy and safety study of abiraterone acetate in chemotherapynaive patients with mCRPC in China, Malaysia, Thailand and Russia. Asian journal of urology. Apr 2017;4(2):75-85.

19. Penson DF, Armstrong AJ, Concepcion R, et al. Enzalutamide Versus Bicalutamide in Castration-Resistant Prostate Cancer: The STRIVE Trial. Journal of clinical oncology : official journal of the American Society of Clinical Oncology. Jun 20 2016;34(18):2098-2106.

20. Shore ND, Chowdhury S, Villers A, et al. Efficacy and safety of enzalutamide versus bicalutamide for patients with metastatic prostate cancer (TERRAIN): a randomised, double-blind, phase 2 study. The Lancet. Oncology. Feb 2016;17(2):153-163.

21. !!! INVALID CITATION !!!

22. O'Donnell A, Judson I, Dowsett $M$, et al. Hormonal impact of the 17 alpha-hydroxylase/C $(17,20)$-lyase inhibitor abiraterone acetate (CB7630) in patients with prostate cancer. British journal of cancer. Jun 14 2004;90(12):2317-2325.

23. Tran C, Ouk S, Clegg NJ, et al. Development of a second-generation antiandrogen for treatment of advanced prostate cancer. Science (New York, N.Y.). May 8 2009;324(5928):787-790.

24. Guerrero J, Alfaro IE, Gomez F, Protter AA, Bernales S. Enzalutamide, an androgen receptor signaling inhibitor, induces tumor regression in a mouse model of castration-resistant prostate cancer. The Prostate. Sep 2013;73(12):1291-1305.

25. Cortes J, Gonzalez JA, Campbell MJ, Cobo E. A hazard ratio was estimated by a ratio of median survival times, but with considerable uncertainty. Journal of clinical epidemiology. Oct 2014;67(10):1172-1177.

26. Song G, Lee C, You D, et al. Prostate-specific antigen response rate of sequential chemotherapy in castration-resistant prostate cancer: the results of real life practice. Prostate international. 2013;1(3):125-132.

27. Smith DC, Dunn RL, Strawderman MS, Pienta KJ. Change in serum prostate-specific antigen as a marker of response to cytotoxic therapy for hormonerefractory prostate cancer. Journal of clinical oncology : official journal of the American Society of Clinical Oncology. May 1998;16(5):1835-1843.

28. de Bono JS, Logothetis CJ, Molina A, et al. Abiraterone and increased survival in metastatic prostate cancer. The New England journal of medicine. May 26 2011;364(21):1995-2005.

29. Loriot Y, Bianchini D, lleana E, et al. Antitumour activity of abiraterone acetate against metastatic castration-resistant prostate cancer progressing after docetaxel and enzalutamide (MDV3100). Annals of oncology : official journal of the European Society for Medical Oncology. Jul 2013;24(7):1807-1812.

30. Azad AA, Eigl BJ, Murray RN, Kollmannsberger C, Chi KN. Efficacy of enzalutamide following abiraterone acetate in chemotherapy-naive metastatic castration-resistant prostate cancer patients. European urology. Jan 2015;67(1):23-29.

\section{Tables}


Table 1. Characteristics of the included clinical trials.

\begin{tabular}{|c|c|c|c|c|c|c|c|c|c|c|c|c|}
\hline Study & Year & NCT & Phase & Line & Patients & $\begin{array}{c}\text { Race or Region } \\
(\%)\end{array}$ & $\begin{array}{l}\text { Treatment } \\
\text { (N) }\end{array}$ & Control (N) & $\begin{array}{l}\text { Median } \\
\text { Age }\end{array}$ & $\begin{array}{l}\text { PSA Decline } \\
\geq 50 \%\end{array}$ & $\begin{array}{c}\text { Median } \\
\text { OS } \\
\text { (month, } \\
\text { AR } \\
\text { inhibitor } \\
\text { vs } \\
\text { Control) }\end{array}$ & $\begin{array}{l}\text { Median PFS } \\
\text { (month, AR } \\
\text { inhibitor vs } \\
\text { Control) }\end{array}$ \\
\hline $\begin{array}{l}\text { COU-AA- } \\
301\end{array}$ & 2012 & 00638690 & 3 & 2 & 1195 & NA & $\begin{array}{c}\text { abiraterone } \\
+ \text { prednisone } \\
(797)\end{array}$ & $\begin{array}{l}\text { prednisone } \\
+ \text { placebo } \\
\text { (398) }\end{array}$ & 69 & $29.5 \%$ vs $5.5 \%$ & $\begin{array}{c}15.8 \text { vs } \\
11.2\end{array}$ & $\begin{array}{l}5.6 \text { vs } 3.6 \dagger \\
8.5 \text { vs } 6.6 \%\end{array}$ \\
\hline $\begin{array}{l}\text { COU-AA- } \\
302\end{array}$ & 2013 & 00887198 & 3 & 1 & 1082 & $\mathrm{NA}$ & $\begin{array}{c}\text { abiraterone } \\
+ \text { prednisone } \\
(542)\end{array}$ & $\begin{array}{c}\text { prednisone } \\
+ \text { placebo } \\
(540)\end{array}$ & 70 & $11.4 \%$ vs $4.4 \%$ & $\begin{array}{c}34.7 \text { vs } \\
30.3\end{array}$ & 16.5 vs $8.3 \dagger$ \\
\hline Sun & 2016 & 01695135 & 3 & 2 & 214 & Asian & $\begin{array}{c}\text { abiraterone } \\
\text { + prednisone } \\
(143)\end{array}$ & $\begin{array}{c}\text { prednisone } \\
+ \text { placebo } \\
(71)\end{array}$ & $68^{*}$ & $54.5 \%$ vs $18.3 \%$ & NR & 5.6 vs $2.8 ※$ \\
\hline Ye & 2017 & 01591122 & 3 & 1 & 313 & Asian & $\begin{array}{c}\text { abiraterone } \\
+ \text { prednisone } \\
(157)\end{array}$ & $\begin{array}{l}\text { prednisone } \\
\text { + placebo } \\
(156)\end{array}$ & $71^{*}$ & $5.1 \%$ vs $1.3 \%$ & NR & NR vs 3.8 \\
\hline STRIVE & 2016 & 01664923 & 2 & 1 & 196 & $\begin{array}{c}\text { Black or African } \\
\text { American (13.4); } \\
\text { White (83.1); } \\
\text { Other (3.5) }\end{array}$ & $\begin{array}{c}\text { Enzalutamide } \\
(198)\end{array}$ & $\begin{array}{c}\text { Bicalutamide } \\
(198)\end{array}$ & $72 / 74$ & $90.9 \%$ vs $42.0 \%$ & $\mathrm{NA}$ & $\begin{array}{l}\text { NR vs } 11.2 \dagger \\
\text { NR vs } 8.3 ※ \\
19.4 \text { vs } 5.7 \#\end{array}$ \\
\hline TERRAIN & 2016 & 01288911 & 2 & 1 & 374 & $\begin{array}{c}\text { White (92.8); } \\
\text { Black or African } \\
\text { American (4.8); } \\
\text { Asian (1.33); } \\
\text { Native Hawaiian } \\
\text { or other Pacific } \\
\text { Islander (0.53); } \\
\text { Other (0.53) }\end{array}$ & $\begin{array}{l}\text { Enzalutamide } \\
\text { (183) }\end{array}$ & $\begin{array}{l}\text { Bicalutamide } \\
\text { (191) }\end{array}$ & 71 & $\begin{array}{c}\text { PFS-1 } \\
\text { 75years: } 83.3 \% \\
\text { vs } 18.5 \% \\
\text { PFS- } \\
\geq 75 \text { years: } 79.3 \% \\
\text { vs } 23.6 \%\end{array}$ & $\mathrm{NA}$ & $\begin{array}{c}\text { PFS } \square \\
75 \text { years: } 16.6 \\
\text { vs } 5.8 \dagger \\
\text { PFS } \\
\geq 75 \text { years: } 13.8 \\
\text { vs } 6.4 \dagger \\
15.7 \text { vs } 5.8 \#\end{array}$ \\
\hline PREVAIL & 2016 & 01212991 & 3 & 1 & 1717 & $\begin{array}{c}\text { North American } \\
\qquad(24.8) ; \\
\text { Europe (53.1); } \\
\text { Other (22.1) }\end{array}$ & $\begin{array}{c}\text { Enzalutamide } \\
\text { (872) }\end{array}$ & $\begin{array}{c}\text { placebo } \\
\text { (845) }\end{array}$ & $72 / 71$ & NA & $\begin{array}{c}35.3 \text { vs } \\
31.3\end{array}$ & 20 vs $5.4 \dagger$ \\
\hline AFFIRM & 2012 & 00974311 & 3 & 2 & 1199 & NA & $\begin{array}{c}\text { Enzalutamide } \\
\text { (800) }\end{array}$ & $\begin{array}{l}\text { placebo } \\
\text { (399) }\end{array}$ & 69 & $54.0 \%$ vs $1.5 \%$ & $\begin{array}{c}18.4 \mathrm{vs} \\
13.6\end{array}$ & $\begin{array}{l}8.3 \text { vs } 2.9 \dagger \\
8.3 \text { vs } 3 ※\end{array}$ \\
\hline
\end{tabular}

NCT $=$ National Clinical Trial; PSA = Prostate Specific Antigen; PFS = Progression-Free Survival; OS = Overall Survival;

NA = Data Not Available; NR= Median Survival Not Reached;

* = Mean age was recorded for the SUN and YE study

$\dagger=$ Radiographic PFS was recorded

※ = PSA PFS was recorded

\# = Overall PFS was recorded

Table 2. Jadad quality assessment for randomized clinical trials.

\begin{tabular}{|l|l|l|l|l|}
\hline Study & Randomization $^{1}$ & Double Blinding $^{2}$ & Follow-up $^{3}$ & ${\text { Total points } / \text { rank }^{4}}^{4}$ \\
\hline COU-AA-301 & 1 & 2 & 1 & $4 /$ High \\
\hline COU-AA-302 & 1 & 2 & 1 & $4 /$ High \\
\hline Sun & 1 & 2 & 1 & $4 /$ High \\
\hline Ye & 1 & 2 & 1 & $4 /$ High \\
\hline STRIVE & 1 & 2 & 1 & $4 /$ High \\
\hline TERRAIN & 2 & 2 & 1 & $5 /$ High \\
\hline PREVAIL & 1 & 2 & 1 & $4 /$ High \\
\hline AFFIRM & 2 & 2 & 1 & $5 /$ High \\
\hline
\end{tabular}

$1=$ Randomization of the studies ( 2 points, computer-generated random number or similar; 1 point, not described; 0 point, non-randomization or inadequate method);

$2=$ Double blinding ( 2 points, identical placebo tablets or similar; 1 point, not described; 0 point, no blinding or inadequate method); $3=$ Follow-up ( 1 point, number and 


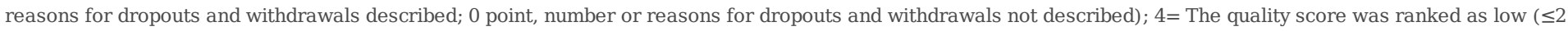
points) or high ( $\geq 3$ points).

\section{Figures}

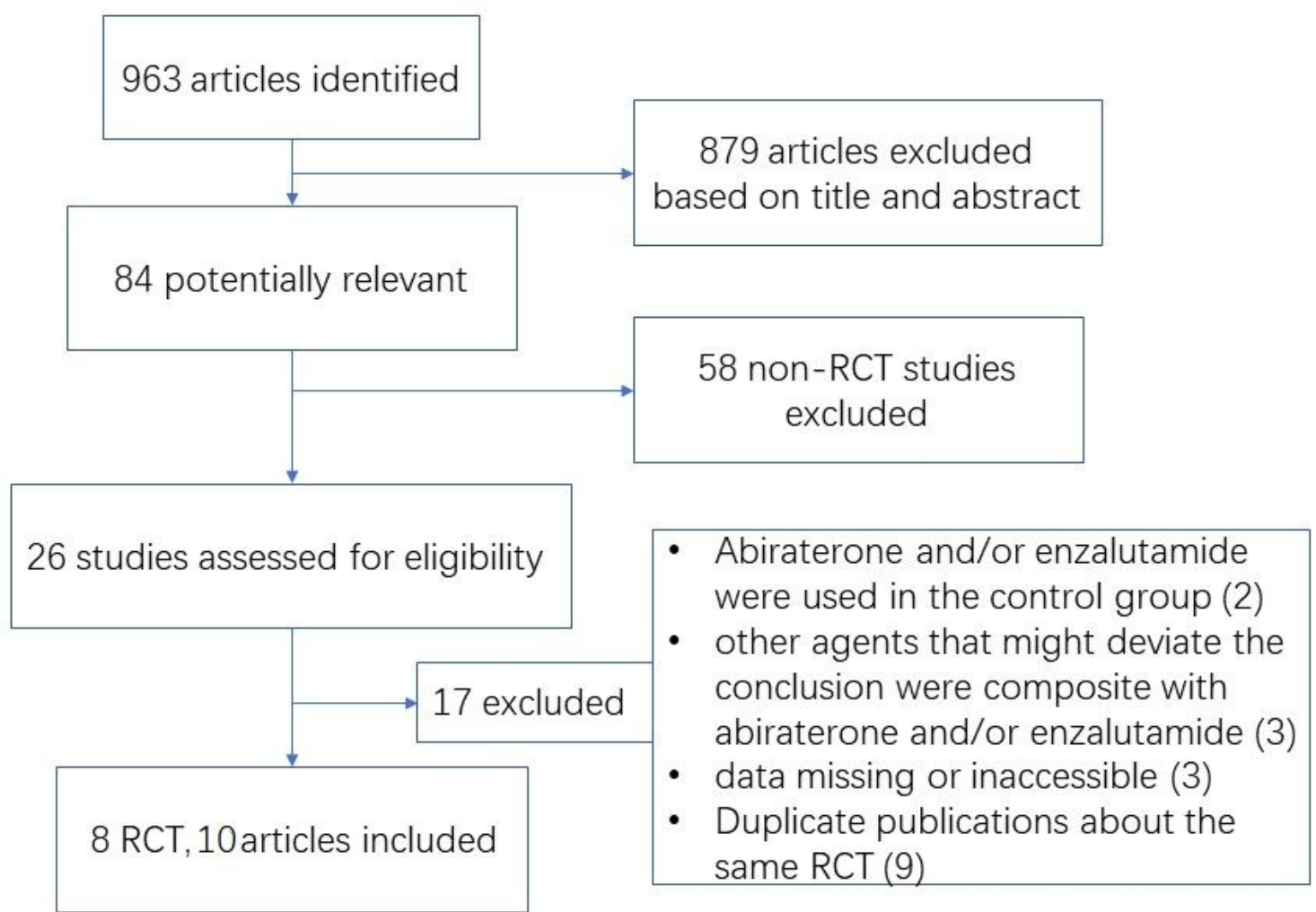

Figure 1

Subgroup analysis of overall survival.

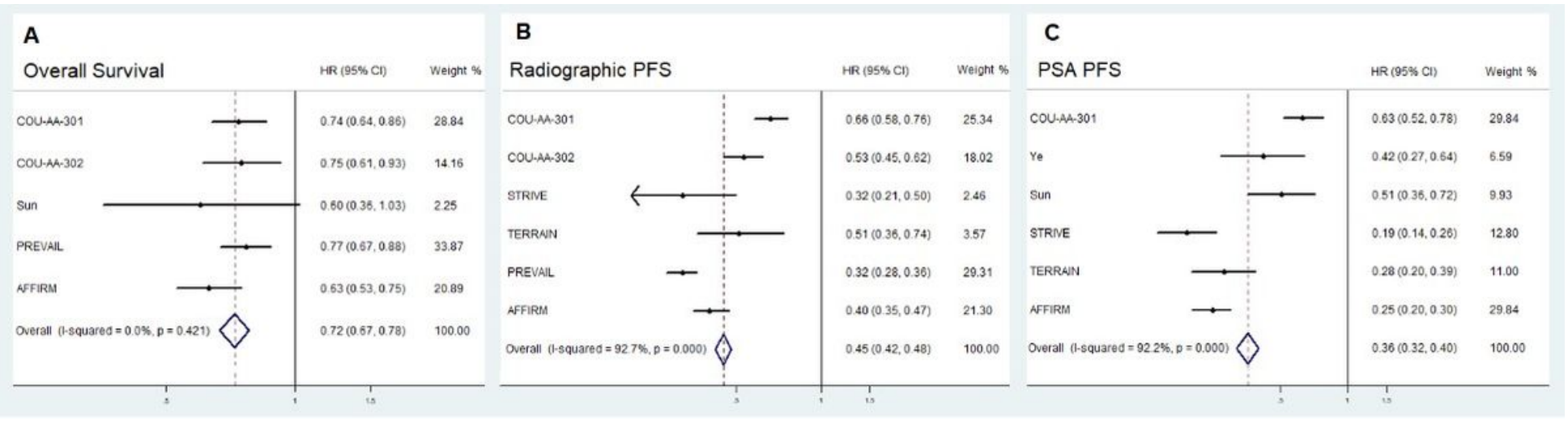

\section{Figure 2}

Subgroup analysis of radiographi progression-free survival and prostate-specific antigen progression-free survival. 
AR Inhibitor Control

\begin{tabular}{|c|c|c|c|c|c|c|}
\hline Study or Subgroup & Events & Total & Events & Total & Weight & M-H, Random, $95 \%$ C \\
\hline AFFIRM & 395 & 731 & 5 & 330 & $12.5 \%$ & $76.41[31.22,187.04]$ \\
\hline C0U-AA-301 & 235 & 791 & 22 & 394 & $14.9 \%$ & $7.15[4.53,11.28]$ \\
\hline COU-AA-302 & 62 & 546 & 24 & 542 & $14.8 \%$ & $2.76[1.70,4.50]$ \\
\hline STRIVE & 156 & 192 & 61 & 195 & $14.8 \%$ & $9.52[5.94,15.26]$ \\
\hline SUN & 78 & 143 & 13 & 71 & $13.7 \%$ & $5.35[2.70,10.63]$ \\
\hline TERRAIN & 151 & 184 & 40 & 191 & $14.6 \%$ & $17.27[10.34,28.86]$ \\
\hline YE & 79 & 157 & 33 & 156 & $14.7 \%$ & $3.78[2.30,6.20]$ \\
\hline Total $(95 \% \mathrm{Cl})$ & & 2744 & & 1879 & $100.0 \%$ & $8.67[4.42,17.04]$ \\
\hline Total events & 1156 & & 198 & & & \\
\hline \multicolumn{7}{|c|}{ Heterogeneity: $\mathrm{Tau}^{2}=0.74 ; \mathrm{Chi}^{2}=65.30, \mathrm{df}=6(\mathrm{P}<0.00001) ; \mathrm{I}^{2}=91 \%$} \\
\hline
\end{tabular}

Odds Ratio

M-H, Random, $95 \% \mathrm{Cl}$

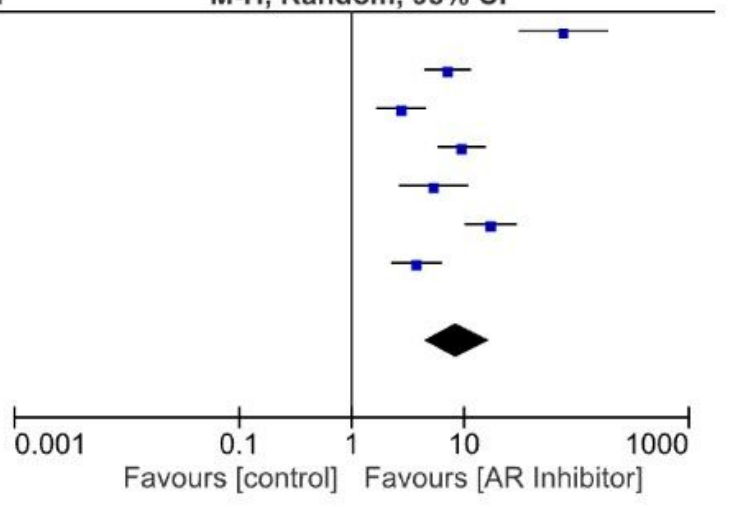

\section{Figure 3}

Prostate-specific antigen response rate subgrouped by androgen receptor signaling-axis inhibitor type.

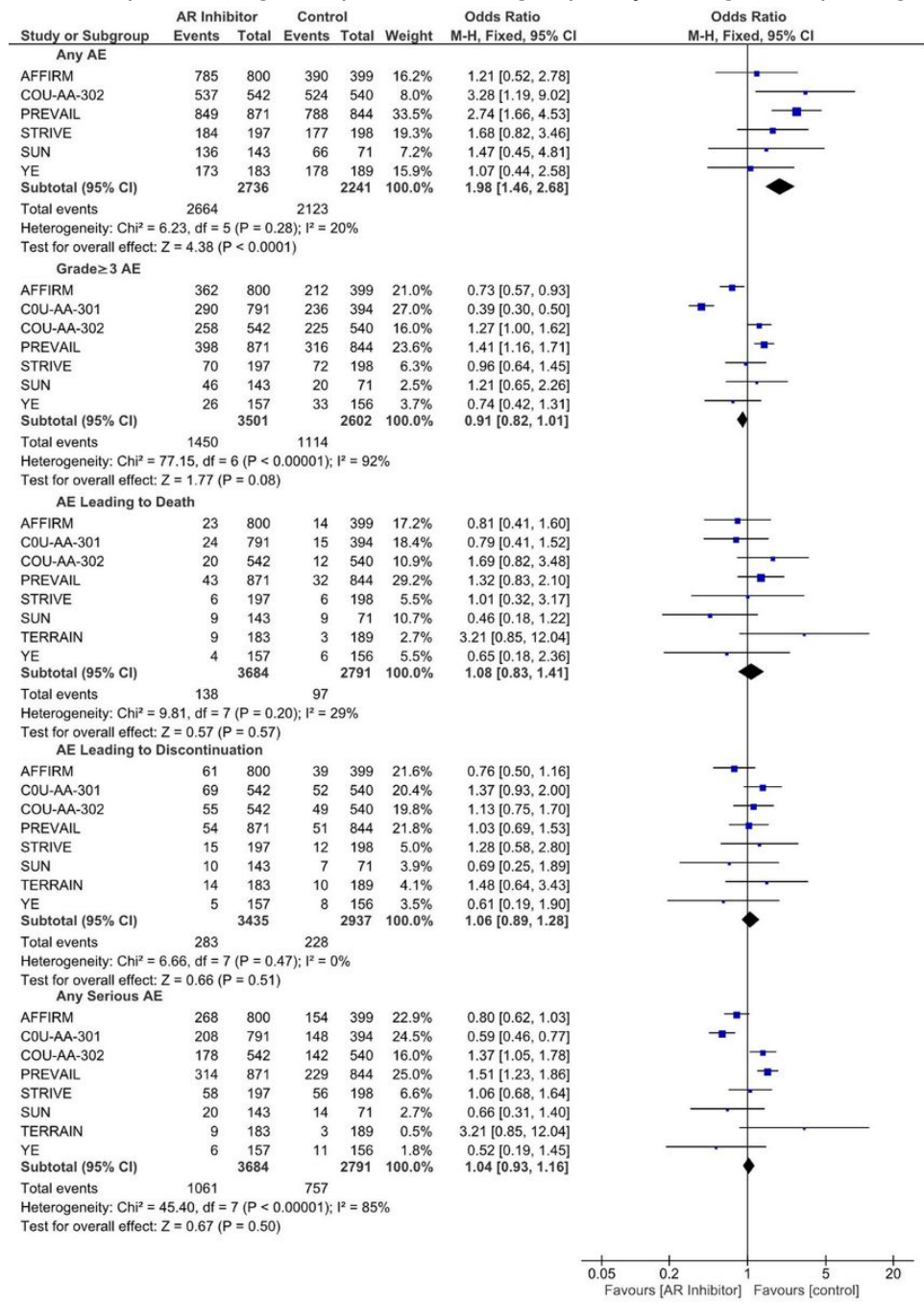

\section{Figure 4}

Any grade adverse events without significant difference between AR inhibitor and control groups. 


\section{A.}

AR Inhibitor Control

Odds Ratio M-H, Fixed, $95 \% \mathrm{Cl}$ Odds Ratio $\frac{\text { Study or Subgroup Eve }}{\text { Any Grade Fatigue }}$

AFFIRM

COU-AA-301

COU.AA-302

PREVAI-
STRIVE

ERRRAIN

Subtotal (95\% CI)

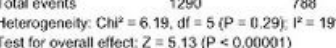

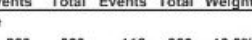
, Fixed, $95 \% \mathrm{C}$ M.H, Fixed, $95 \%$

Any Grade Back Pain

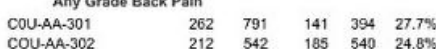

$\begin{array}{llllll}\text { COU-AA-302 } & 212 & 542 & 185 & 540 & 24.8 \% \\ \text { PREVAI } & 249 & 371 & 189 & 844 & 302 \%\end{array}$

PREVAL

STRIVE
SUN

SUNRAIN

YE

Total events

$\begin{array}{lllll}35 & 197 & 31 & 196 & 5.6 \%\end{array}$

$\begin{array}{llllll}19 & 143 & 9 & 71 & 2.3 \% \\ 35 & 183 & 34 & 189 & 6.05 \%\end{array}$

$1.24[0.95,1.60]$

$1.12[0.88,1.43]$

1.259 .96 .1 .506

$1.53[1.00,2.33\}$

$1.54[0.95,2.48]$
$1.34[1.20,1.49]$

$\begin{array}{lll}2392 & 100 \% & 0.62[0.28,1.36]\end{array}$

$0.89[0.69 .1 .15]$

$1.23[0.96,1.56]$

$1.39[1.11,1.73]$

$106[0.45 .247$

823

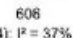

Teterogeneity: Chi $=9.57, \mathrm{df}=6(\mathrm{P}=0.14)$
Test for orerall effect: $Z=2.12(P=0.03)$

Any Grado Hot Flush
AFFIRM
$\begin{array}{lll}\text { COU-AA-302 } & 162 & 800 \\ \text { PA-S12 } & 542\end{array}$

\begin{tabular}{lrrrrr} 
COU-AA-302 & 212 & 542 & 41 & 399 & $17.8 \%$ \\
\hline & 1570 & $46.1 \%$
\end{tabular}

PREVAIL

STRIVE

(1.23[0.96, 1.58]

$\begin{array}{llllll}31 & 197 & 19 & 190 & 6.5 \% & 2.59[1.91,3.52]\end{array}$

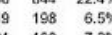

$1.76[0.96,3.23]$

$1.38[0.75,2.55]$
$1.76[1.50,2.06]$

Subtotal $(95 \%$
Total events

2593

$\begin{array}{rrr}189 & 7.2 \% \\ 2170 & 100.0 \%\end{array}$

332

Heterogeneity, Chi $=16.25$, of $=4(P=0.003$;

Any Grade Diarrhea

COU AA- 30

COU-AA-302

PREVAL.

STRIVE

TERRAIN

$\begin{array}{lllll}158 & 700 & 70 & 399 & 18.8 \% \\ 158 & 798 & 394 & 15.9 \%\end{array}$

$\begin{array}{lllll}12 & 542 & 185 & 540 & 28.95 \\ 146 & 871 & 121 & 844 & 26.25\end{array}$

$\begin{array}{rrr}185 & 540 & 28.9 \% \\ 121 & 844 & 26.2 \% \\ 28 & 198 & 6.5 \%\end{array}$

Total events $723 \quad 479$

$\begin{array}{llllll}21 & 183 & 17 & 189 & 3.85 \% & 0.57[0.31[0.67,2.57]\end{array}$

Test for orerall effect: $Z=2.96(P=0.003)$

Any Grade Arthralgia

$\begin{array}{lrrrrrr}\text { COU-AA-301 } & 239 & 791 & 95 & 394 & 27.0 \% & 1.36[1.03,1.80] \\ \text { COU-AA-302 } & 212 & 542 & 185 & 540 & 34.4 \% & 1.23[0.96,1.56] \\ \text { PREVAIL } & 186 & 871 & 136 & 844 & 33.2 \% & 1.41[1.11,1.81] \\ \text { SUN } & 17 & 143 & 5 & 71 & 1.8 \% & 1.78[0.63,5.04]\end{array}$

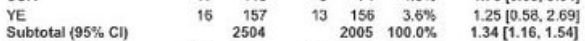

Subtotal $\{95 \% \mathrm{C}$ 434

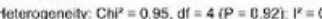

Test for overall effect: $Z=3.99(P<0.0001)$

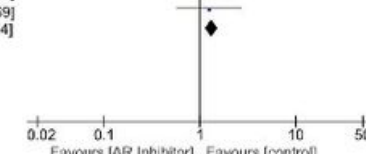

B.

AR Inhibitor Control

Odds Ratio

Study or Subgroup Events Total Events Total Woight M-H, Fixed, 95\% C

Odds Ratio

$\begin{array}{lrlllll}\text { COU-AA-301 } & 88 & 791 & 32 & 394 & 22.1 \% & 1.42[0.93,2.16] \\ \text { COU.A. } 302 & 118 & 542 & 71 & 540 & 32.4 \% & 1.84[1.33,2.54] \\ \text { PREVAIL } & 124 & 871 & 35 & 844 & 17.7 \% & 3.84[2.60,5.66]\end{array}$

$\begin{array}{lllllll}\text { STRIVE } & 24 & 197 & 10 & 198 & 5.1 \% & 2.61[1.21,5.61]\end{array}$

$\begin{array}{lllllll}\text { SUN } & 23 & 143 & 9 & 71 & 5.9 \% & 1.32[0.58,3.03 \mid\end{array}$

$\begin{array}{lllllll}\text { TERRAIN } & 26 & 183 & 12 & 189 & 5.9 \% & 2.44[1,19,5.00]\end{array}$

$\begin{array}{lrrrrrr}\text { YE } & 23 & 157 & 22 & 156 & 11.0 \% & 1.05[0.56,1.97] \\ \text { Subtotal }(95 \% \mathrm{Cl}) & & 2884 & & 2392 & 100.0 \% & 2.06[1.71,2.47]\end{array}$

Total events

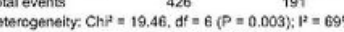

Test for overall effect: $Z=7.76(\mathbb{P}<0.00001)$

$\begin{array}{ccccccc}\text { Any Grade Hypokalemia } & & & & \\ \text { COU-AA-301 } & 143 & 791 & 36 & 394 & 37.9 \% & 2.19[1.49,3.23]\end{array}$

$\begin{array}{lrlllll}\text { COU-AA-301 } & 143 & 791 & 36 & 394 & 37.9 \% & 2.19[1,49,3.23] \\ \text { COU-AA-302 } & 91 & 542 & 68 & 540 & 54.5 \% & 1.40[1.00,1.97]\end{array}$

$\begin{array}{lrrrrrr}\text { SUN } & 37 & 143 & 8 & 71 & 7.6 \% & 2.75[1.20,6.27] \\ \text { Subtotal }(95 \% \mathrm{Cl}) & & 1476 & & 1005 & 100.0 \% & 1.80[1.42,2.30]\end{array}$

Total events

271 112

Test Generily. Chi $=4.12 . \mathrm{df}=2(\mathrm{P}=0.13), \mathrm{P}=51 \mathrm{~s}$

Tol tor overaif eflect: $Z=4.79(P<0.00001)$

Any Grade Fluid Retention or Edema

$\begin{array}{lllrrrr}\text { COU-AA-301 } & 261 & 791 & 94 & 394 & 33.9 \% & 1.57[11.19,2.07]\end{array}$

$\begin{array}{lrrrrrr}\text { COU.AA.302 } & 150 & 542 & 127 & 540 & 37.1 \% & 1.24[0.95,1.64] \\ \text { PREVAIL } & 100 & 871 & 69 & 844 & 25.0 \% & 1.46[1.06 .201]\end{array}$

$\begin{array}{lrrrrrrr} & 100 & 871 & 69 & 844 & 25.0 \% & 1.46[1.06,2.01] \\ \text { SUN } & 10 & 143 & 8 & 71 & 4.0 \% & 0.59[0.22,1.57] \\ \text { Subtotal }(95 \% \mathrm{Cl}) & & 2347 & & 1849 & 100.0 \% & 1.38[1.17,1.63]\end{array}$

298
$\mathrm{R}^{2}=32 \%$

Test for overall effect: $Z=3.88(p=0.0001)$

C.

Control Od Ratio Study or Subgroup Events Total Events Total Weight M.H, Fixed, 95\% CI Gradez 3 Hypertension

$\begin{array}{lllllll}\text { COU-AA-301 } & 10 & 791 & 1 & 394 & 3.5 \% & 5.0310 .64 .39 .45\end{array}$ $\begin{array}{lllllll}\text { COU.AA-302 } & 21 & 542 & 16 & 540 & 41.1 \% & 1.32[0.68,2.59\end{array}$ STRIVE $\quad 10 \quad 197 \quad 3 \quad 198 \quad 7.61 \%$ $\begin{array}{lllll}\text { Subtotal }(95 \% \mathrm{Cl}) & 2401 & 1976 & 100.0 \% & 2.60[1.79,3.79\end{array}$

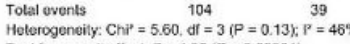
Tost for owerall elfoct: $Z=4.98(P<0.00001)$

Grade $\geq 3$ Pain in Extremity

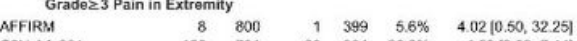
$\begin{array}{lllllll} & 156 & 791 & 20 & 394 & 90.3 \% & 4.59[2.83,7.4\end{array}$

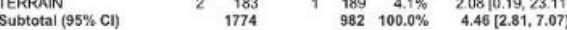

otal events $\quad 166 \quad 22$

Test for overall effect $Z=6.36(P<0.00001)$

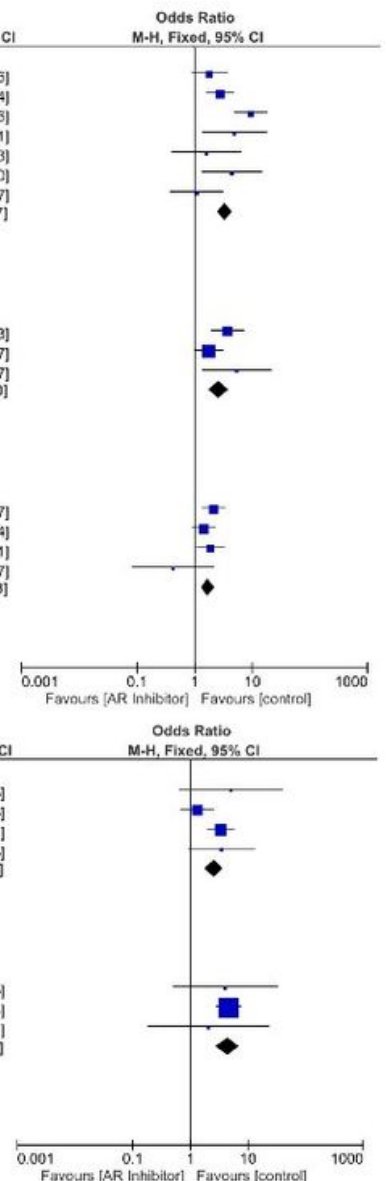

Figure 5

High grade ( $\geq$ grade 3 ) adverse events without significant difference between androgen receptor inhibitor and control groups.

\section{Supplementary Files}

This is a list of supplementary files associated with this preprint. Click to download.

- supplementary.docx 